\section{Wellcome gears up production of AIDS drug}

\section{London}

CONFIDENT that the first approval for the use of its anti-AIDS drug, Retrovir (trade name for AZT), is just around the corner, Wellcome plc is busily preparing itself for the anticipated demand. At a capital cost of $£ 17$ million, additional general purpose plants are being constructed both at Dartford, Kent, and at Greenville, Tennessee.

But even with their new production capacity, the company may not be able to meet estimated worldwide demand, in which case, presumably to avoid the kind of criticism that followed its initial allocation of the drug solely to the United States, Wellcome would allocate supplies on a geographical basis according to the number of reported cases.

Wellcome makes the drug (3' -azido-3' deoxythymidine; AZT), by chemical synthesis from thymidine, which in turn is chemically synthesized by another company, whose identity is secret. Both companies are scaling up their chemical syntheses, which involve sixteen steps.

By May this year, Wellcome expects to have enough of the drug to meet the demand for its use in AIDS (acquired immune deficiency syndrome) patients who are seriously ill with pneumonia caused by Pneumocystis carinii, a group that has responded well to the drug in clinical trials. But if worldwide approval for use of the drug in patients with serious AIDSrelated complex (ARC) was also soon granted, supplies would not meet demand. On existing figures there are about $15-20,000$ patients in each category, needing an average of about one gram a day of the drug continually.

Approval for use of the drug in one or both conditions is expected from the US Food and Drug Administration in "five or six weeks", according to a Wellcome spokesman. And the UK Committee on Safety and Drugs is considering an application based on the same data. Wellcome will be submitting similar applications to other major European countries soon. In addition, clinical trials will test the value of the drug, alone or in combination therapy, in less severe cases of AIDS or ARC.

Responsibility for Retrovir production changed hands last week with the resignation of Dr Ronald Cresswell, who became the director responsible for coordinating Wellcome's US and UK research and development after the departure of Sir John Vane. No direct replacement has been made. Instead, Dr Trevor Jones takes over UK responsibilities and Dr Howard Schaeffer runs the US side.

Peter Newmark

\title{
US Navy torpedoes plan with NASA for ocean sensing satellite
}

\section{Washington}

THE US Navy is to scrap NROSS, the Navy Remote Ocean Sensing Satellite. The decision has not only dealt a telling blow to the future of the Navy's global weather and oceanographic forecasting, but has caused consternation among the Navy's partner agencies. The decision has forced NASA (National Aeronautics and Space Administration) to look for a new vehicle to carry a scatterometer, considered essential to the future of civilian oceanographic research.

NROSS began life in the 1985 fiscal year when it received formal budgetary approval. The satellite was to travel in a Sunsynchronous polar orbit, carrying a lowfrequency microwave radiometer to provide all-weather high resolution measurements of sea surface temperature as well as an altimeter to measure waves and eddies. The Navy planned to include its own scatterometer on NROSS, but NASA offered to provide the Navy with NSCAT, an improved version of the scatterometer flown on the successful 1987 Seasat mission.

The Navy accepted and signed an agreement with NASA in July 1985. NSCAT transmits $14-\mathrm{GHz}$ pulses towards the Earth, recording the reflected microwave signals. Ground-based computers interpret satellite telemetry to construct a map of ocean winds. NSCAT was to provide scientific data for NASA and operational data for the Navy.

The Navy's plans have been scuppered by rising costs in 1986. By July last year, the estimated cost of the satellite was $\$ 420$ million, $\$ 150$ million more than expected. By November, Assistant Secretary of the Navy Melvyn Paisley had called for a study of ways out of the dilemma, and the NROSS programme office presented three options at a meeting on 11 December: find the money from somewhere else in the Navy's budget, replace the lowfrequency microwave radiometer with one costing less or cancel the programme.

Because the alternative radiometer would not work under cloudy conditions and with the prospects of finding the extra money only slim, it was decided to cancel the programme.

The oceanography "union" in the US Navy does not have the clout of others, such as those advocating construction of aircraft carriers or destroyers. There are also indications that the large cost increase for NROSS should not have come as a surprise, as the Navy had modified its requirements for the satellite. Thus, responding to concern created by the shuttle accident, the Navy had attempted to make contractors liable for mission failures, to which contractors had responded by raising costs.

Attempts by supporters of NROSS to intercede have so far failed. Both NASA administrator James Fletcher and National Science Foundation director Erich Bloch wrote to Navy Secretary John Lehman urging him to retain the programme. Carl Wunsch, James O'Brien and Walter Munk, three of the four holders of Secretary of the Navy Research Professorships, also protested. Unpersuaded, Lehman agreed on 15 December to scuttle the satellite.

Following the Navy decision, Fletcher wrote to William Taft IV, deputy secretary of defence on 17 December, saying that "the cancellation of NROSS would set a bad precedent for other ongoing and future cooperative programs between DOD [Department of Defense] and NASA"

In a conciliatory response dated 20 January, Taft declined to change the decision but suggested that NSCAT might find a home in the Defense Meteorological Satellite Program, an option already being explored by NASA. The Air Force has now begun a study of that proposal, as well as the possibility of including NSCAT in DOD's Space Test Program. These options could be acceptable to NASA, since they would permit NSCAT to fly concurrently with TOPEX/POSEIDON, the joint NASA-French oceanography satellite due to be launched in December 1991 NASA is also investigating putting NSCAT on TOPEX.

Cancelling NSCAT, estimated to cost $\$ 130$ million, would be expensive for NASA. The agency has already spent $\$ 30$ million on the project, and an additional $\$ 30$ million would be needed to end the programme in an orderly fashion. But William Townsend of NASA's Oceanic Processes Program says he is "extremely optimistic" that something can be worked out to allow NSCAT to complete its mission.

Wunsch calls the Navy decision on NROSS "extremely short-sighted". $\mathrm{He}$ argues that cancelling NROSS will have severe repercussions for the Navy in the next $10-15$ years when forecasting global oceanographic conditions will be critically important for new weapon systems.

D. James Baker, president of the Joint Oceanographic Institutions, says wind data provided by NSCAT are essential for WOCE, the World Ocean Circulation Experiment. Baker says a delegation of oceanographers is hoping to meet Navy officials soon to discuss the future of Navy's oceanographic programme.

Joseph Palca 